\title{
Interpretación histórica de las relaciones hipano-chilenas: el sentido de una pregunta
}

\author{
Joaquín Fermandois
}

El "caso Pinochet" apareció como una sorpresa ante el público chileno, y la reacción de los actores políticos reveló, en los dos principales sectores del espectro político, un grado importante de desconocimiento de la política mundial y de las motivaciones de la acción de los actores internacionales. El artículo explora la posibilidad de explicar esta situación, de entender la importancia simbólica de Chile ante el mundo; de mostrar las razones históricas en las relaciones hispano-chilenas a partir de 1936 hasta la década de los noventa, que ayudan a entender el desarrollo de este "caso" en la actualidad; y de mostrar las oportunidades y peligros que este hecho tiene especialmente para los países débiles en el sistema intemacional contemporáneo.

\section{El "caso Pinochet" y las inversiones}

En el pasado cercano, dos hechos han venido a colocar en el estrellato nuestras relaciones con la Madre Patria, España. Por un lado, el "caso Pinochet", que en sus inicios estremeció al país como nada lo hacía desde los días del plebiscito de 1988. Por otro, la nueva España, nueva no sólo por la democracia y estabilidad, inéditas en su historia política del $X] X$ y del $X X$, sino que nueva por su modernización exitosa de los últimos 40 años, adquirió un protagonismo imprevisto -a los ojos criollos- en la economía chilena.

Otrora, hace apenas 30 años, el ogro extranjero eran los capitales norteamericanos; hoy día, por la llamada globalización y la evolución de las cosas, el origen puede ser diferente, e incluso se ha dicho que sería ocioso preguntarse por dicho origen, salvo que no sea ilegítimo, es decir, de origen ilegal. Los capitales se mueven cada día más libremente, y a lo que parece hay que 
apuntar, es a la eficacia y seriedad de los equipos que elaborarán la estrategia y podrán en marcha la respectiva empresa.

Se ha hablado de una planificación de parte de la Unión Europea para privilegiar la presencia española en Hispanoamérica. Como sea, lo abrupto del fenómeno, el volumen de la inversión, el que se haya realizado en su primera fase junto al fracaso de un intento de empresarios chilenos por efectuar un control en conjunto, y la coincidencia con los efectos de una crisis que ha llevado al primer y claro retroceso en el crecimiento en los 15 años pasados, y su secuela de desempleo; la coincidencia también con el "caso Pinochet", cuyas paradojas han dejado perplejos -o esperanzados, en ambas categorías- a diversos sectores en Chile. Las inversiones han arribado, por añadidura, en un momento en el que el ambiente general es de pesimismo y fatalidad y de una en general superficial "crítica de la cultura" que, no por exagerada deja de ser menos inquietante.

Esta sensación de extrañeza ante el poder transformador de la economía moderna ha sido bastante universal. Era lógico que en una civilización en la cual surgiera la autocrítica como un rasgo central de su alta cultura y de su política, tenía que nacer asimismo una desconfianza, cuando no un franco rechazo, a las virtualidades de la economía mundial de mercado que, desde hace varios siglos viene transformando la faz de la tierra. Dicho sea de paso que, dentro de su mismo espíritu "transformista", aunque con un constructivismo centrado en el poder político, los modelos alternativos no dejaron de multiplicar los males que hoy se le presumen exclusivamente a la economía mundial de mercado.

En sí mismo, el asunto de las nuevas y gigantescas inversiones de origen español no levantarán más polvareda que la que normalmente se produce ante un cambio brusco y espectacular de propiedad. Sólo debemos anotar que, dentro de la perspectiva de "juego de espejos" que constituye el ángulo visual de este trabajo, este hecho nos debe llevar a pensar los vínculos entre la civilización iberoamericana, por llamarla de una manera, y la economía moderna. Es muy conocido el hecho de que la península ibérica no participó de la creación de lo moderno en el ámbito económico, salvo en algunas áreas reducidas. Pero en estas últimas cuatro décadas, España principalmente, ha dado un salto gigantesco a la modernidad económica. Este desarrollo, desde luego, no deja de traer sus problemas, como se repite incansable y no sin un dejo de manierismo en muchos círculos intelectuales. En parte corresponde a 
la condición del hombre en la historia. Cuando se supera un desafío, en vez del fin del túnel, vemos la entrada a uno nuevo.

Lo importante que hay que retener, es que en determinadas circunstancias, donde la voluntad de algunos actores sociales es fundamental, se da la posibilidad cierta de adquirir los instrumentos organizativos y productivos que son inherentes a la economía moderna. Estas voluntades y habilidades son las que una clase dirigente, o más restringidamente, una clase política, puede inspirar en una sociedad. La mirada a la España contemporánea puede esclarecer algunos aspectos de nuestra propia situación en el contexto de los desafíos del presente. Aunque en Chile los cambios económicos y sociales han sido tectónicos, este país todavía no es ni tiene asegurado llegar a ser un país moderno, una sociedad básicamente de clase media, como es el rostro de las modernas democracias industriales. Desconocer este hecho puede ser tan peligroso como lo es el utilizar las técnicas agoreras de los showmen y showomen, como de aquellos intelectuales que trafican con el anuncio del comercio de la catástrofe.

\section{El Chile post-autoritario y el caso Pinochet}

No son, sin embargo, en sí mismas, las recientes inversiones de origen español las que han provocado una mirada especial hacia la Madre Patria. Es su vinculación con el "caso Pinochet" lo que ha potenciado la mirada problemática a las relaciones entre ambos países. Se trata del aspecto en el cual centraré este trabajo.

La espectacularidad del "caso Pinochet" volcó una situación que parecía consolidada desde el punto de vista chileno, como asimismo, desde el punto de vista oficial del gobierno español como de una parte de su opinión pública, o al menos de su "clase discutidora". Es cierto que durante los noventa hubo siempre en Chile, un sector que había cuestionado muchos aspectos de la transición a la democracia, y que su voz había crecido en el año que precedió a la detención de Pinochet. Las insuficiencias de la modernidad chilena, los oscuros sentimientos entrecruzados de arrogancia y resentimiento que han alimentado a una esfera considerable de la vida social del país, los efectos de la "crisis asiática", se juntaron con el sector que cuestionaba el tipo de transición pactada, transición que fue una transacción. Estas críticas se catapultaron 
con una fuerza no sospechada a raíz de la detención de Augusto Pinochet en Londres en octubre de 1998.

Sin embargo, en lo básico, y a pesar de todo lo que se dice de "superar el pasado" y de lograr una especie de mítica "reconciliación", en comparación con la historia del siglo XX al menos, nunca los chilenos estuvieron tan conciliados como en esta década de los noventa; en lo esencial, nos parece que todavía lo están, y es la base de la consolidación del sistema post-autoritario que no parece estar seriamente resquebrajado. Podríamos abundar en este aspecto, pero en aras de la concisión, sólo hay que añadir que un ingrediente de la estabilidad consistía en que una de las miradas del mundo sobre Chile era en ponerlo como un (buen) ejemplo de modernización política y económica, la estrella de América Latina, lo que llegó incluso a jugar un papel en la política rusa de los noventa (en su momento Alexander Lebed se comparaba con Pinochet; hoy, más a tono con los medios de comunicación de masas, se compara con De Gaulle).

En el deleite de estos años, en Chile, unos y otros han efectuado su propio "olvido": si por una parte una gran mayoría parecía indiferente al exterminio físico de la cúpulas políticas en los años setenta, otros olvidaban que el modelo al que quisieron orientar el país durante los años setenta ha sido inseparable de atrocidades no contadas y genocidios. El no haber querido verlos como tales no es muy diferente a decir "yo no sabía" al referirse a los excesos de los años setenta. Un tercer grupo, ínfimamente minoritario, a lo largo de los noventa rechazó todo el proceso de transición y tomó la bandera de los derechos humanos para denunciar al sistema democrático relativamente consensuado. Para estos, parece ser que la confrontación ideológica con la que se quiso redefinir al país sigue vigente, sin memoria de lo sucedido entretanto, para no hablar del modelo o utopía retrospectiva hacia la cual miran. Aquí, naturalmente, excluyo a los familiares de las víctimas, aunque no se debe olvidar que, cierto que en números muy diferentes, se encuentran en varios sectores del espectro.

Aunque el ambiente se había agriado en este país entre 1997 y 1998, la detención de Pinochet en Londres puede asimilarse al pavoroso estallido de una bomba de tiempo en un mercado atestado de gente. Sobre esto se ha escrito y dicho bastante, y este trabajo abundará sobre el tema. Nos interesa llamar la atención hacia dos tipos de perplejidades que se ocasionaron en Chile. 


\section{Perplejidad: el desafecto europeo}

Por una parte, el sector que se sentía cercano al gobierno militar, o que siguió pasivamente los acontecimientos a partir de 1973, y desde luego los representantes de ese gobierno, no podía salir de su aturdimiento ante un hecho que a su juicio, y me parece que en los hechos también, violaba las reglas del juego de la vida internacional. No comprendía cómo la aceptación casi universal del "modelo chileno", esto es, las "reformas económicas" que han recibido un aplauso a granel, se transformó por un golpe de látigo en un caso de paria internacional. Desde esta perspectiva, se recurrió a la consabida "teoría de la conspiración" para explicar la reacción internacional contra el gobierno militar, especialmente contra el mismo Pinochet. Jamás se comprendió la profundidad del repudio internacional que provocó el 11 de septiembre y las características del gobierno militar en sus primeras etapas. Esta impresión no pudo ser borrada jamás y, probablemente, no lo será jamás en la medida que persista una imagen universal acerca de nuestro país: Pinochet, con expresión adusta, mirando a través de gafas oscuras, fue consagrado como la imagen demoníaca que venía de América latina.

Todavía en los ochenta, durante las tensas jornadas de las protestas, el Ministro de Relaciones Exteriores de Francia, Claude Chesson, dijo que "el general Pinochet era una maldición para su pueblo". Semanas después, antes de entrevistarse con Castro en La Habana, hizo un panegírico del líder caribeño, y nadie notó una disonancia; esta situación se repite con la declaración de rechazo a la Ley Helms-Burton y afirmación del principio de extraterritorialidad de la ley hace casi un año, seguida por la detención de Pinochet con la colaboración de los gobiernos español e inglés, y el cerrado aplauso de sus respectivas opiniones públicas. Castro sigue encontrando una recepción rayana en la adulación en los medios políticos europeos.

Este ejemplo nos debe llevar más allá del protagonismo que en las últimas décadas han llegado a tener la defensa de los derechos humanos por parte de lo que podríamos llamar una opinión pública internacional, y que en los sistemas democráticos ningún gobierno puede ignorar impunemente. Este es un hecho positivo que ha resultado del siglo XX, siempre y cuando se desarrolle sin un doble standard aberrante, y se imponga una jerarquía razonable acerca de la significación de las violaciones a los derechos humanos. Este sería el aspecto positivo del caso Pinochet. Por lo demás, en la existencia histó- 
rica de hombres y pueblos, sabemos que el bien y el mal se nos aparecen en un extraño estado de confusión: El arte de la política en su más alto sentido consiste en poder establecer una jerarquía de importancia, que aproxime las necesidades y los valores.

En el caso que nos ocupa, se constata -en relación a Castro- que la promoción de los derechos humanos va unida no sólo al ejercicio de un abierto doble standard, que afecta no sólo a la viabilidad política del país al que se presiona, sino que también contra el parecer de una mayoría de quienes encabezaron la oposición al gobierno militar. Más aún, en el caso de los gobiernos de Madrid y Londres, va contra los ejemplos de su propia historia más o menos reciente y de la posibilidad de lograr la paz en el País Vasco y en Irlanda del Norte.

\section{Acerca de la incomprensión: aprendizaje (I)}

Pero lo que interesa en este aspecto, es destacar la perplejidad de una parte de los chilenos. Este sector ha sido incapaz de comprender la profundidad del rango simbólico que adquirió el caso chileno. En parte por responsabilidades originadas en Chile, en parte porque el mundo "eligió" a Chile como el malvado de la película. Esta ha sido una experiencia que está al interior de esa parte -limitada- del alma europea que mira hacia Chile. Existe un provincianismo en la cultura chilena que resulta en que sectores que por educación y posibilidades de vida debería tener una visión más sofisticada de la realidad mundial, sin embargo, trasladan una visión de "familia chilena", un tipo de cultura en la cual las vinculaciones personales, están teñidas de posición de poder social. Creen que pueden funcionar con la misma efectividad -positiva o negativa- en otra realidad. Es impresionante como las reacciones de incredulidad de este sector ante el caso Pinochet, demuestran cómo no se comprendió nunca la naturaleza del rechazo europeo al gobierno militar.

Este repudio estuvo acicateado por la amplia información que se le otorgó a los excesos que siguieron al 11 de septiembre de 1973 y los siguientes años. Constituyó una causa que además dio sentido político a los herederos del 68 en Europa Occidental, cuando las perspectivas del brinco a un estadio radicalmente diferente del desarrollo humano, el fin de la necesidad, comenzaba a esfumarse en sus propios profetas. Además, era fácil, aunque intelectual- 
mente insostenible, poner el caso chileno en las coordenadas de "fascismo" y antifascismo", espectro que, a raíz del shock cultural de los sesenta, recobró algo del magnetismo que ostentó en los años de la guerra civil española.

Este clima de ideas y sentimientos no podía ser producto de una "conspiración" o "mala información", como sostenían no sólo los miembros del gobierno militar chileno, sino que una fuerte corriente de chilenos que lo apoyaba. Un observador podía caer en la tentación de mirar el silencio europeo sobre lo que ocurría en Camboya -las primeras medidas de los genocidas fueron aplaudidas incluso desde las columnas de Le Monde-, o la indiferencia ante el éxodo de los refugiados vietnamitas, ayudado parcialmente sólo por EE.UU., y hubiera creído hallarse ante una "conspiración del silencio". Aunque quizás existieron algunos intentos en este sentido, lo importante es el fenómeno cultural que lo posibilitó. El "caso chileno" era producto de un estado de ánimo en Europa Occidental, que tenía su eco o era compartido por razones relativamente análogas en el mundo entero. Pero el fenómeno culturalmente más interesante -fascinante en este sentido- es el europeo. Con todo, la reacción europea no era producto originado en el 11 de septiembre.

Existió otro fenómeno que hace comprensible esta reacción de doble medida, según la ocasión. El gobierno militar chileno pasó a simbolizar la "antiutopía" de la última década y media de la Guerra Fría, casi solamente porque fue precedido por una "utopía". Esta fue el atractivo irresistible que Allende y la Unidad Popular ejercieron no sólo en el entorno regional latinoamericano o en los sistemas marxistas por razones obvias, sino que más fuertemente, casi unánimemente, en Europa Occidental. Aquí debemos incluir a la opinión pública de la España del franquismo tardío, e incluso a parte de las filas de gobierno. Esta fascinación, que aquí no podemos exponer en profundidad, es la que convertiría a este remoto país en la "experiencia chilena", objeto de fantasías, repudios y expectativas que poco tenían que ver con la realidad concreta de Chile.

El atractivo irresistible de la "experiencia chilena" no fue un producto exclusivo de la izquierda europea, lo que se debe comprender a cabalidad al momento de analizar el caso Pinochet. La simpatía casi unánime con la figura de Allende y con lo que se suponía era el proyecto de la Unidad Popular, caló hondo en prácticamente todo el espectro político público europeo. Sólo en los gobiernos, algunos personeros, en conversaciones de pasillo, en la intimidad de una entrevista confidencial, expresaban algunas dudas o aprensiones. Unos pocos diarios de gran influencia pusieron el acento en el desastre económico, 
pero aún en estos casos, en los años siguientes al 11 de septiembre (The Economist es el caso más espectacular), fueron cambiando totalmente de posición al mirar hacia Chile.

¿Era una simpatía con las ideas de la Unidad Popular? Esto podría decirse, en términos estrictos, de agrupaciones como los partidos comunistas italiano y francés, e incluso aquí con prevenciones. Es conocido como Enrico Berlinger justificó su propuesta de "compromiso histórico" aludiendo al caso chileno. Era cierto en los remanentes de 1968, todavía fuertes en el mundo estudiantil y académico. Pero en la izquierda no marxista, en la socialdemocracia, no se podría encontrar ninguna comunión ideológica, si es que se toman en serio los postulados de la subcultura política chilena que dominaba la Unidad Popular. Socialismo con democracia siempre era traducido en Chile con la pregunta, ¿qué tipo de democracia? Las obras de Joan Garcés son bastante elocuentes en mostrar una estrategia que tenía como paradigma a los sistemas marxistas clásicos, aunque fuera diferente la estrategia política para acceder a ellos. Pero la lectura de esta izquierda europea -Brandt y Mitterrand son ejemplos bien diáfanos en este sentido- estaba convencida del carácter "occidental" del socialismo del que se hablaba en Chile.

De una manera más difusa, pero también emotiva, en sectores de centro y aún de derecha, se hacía una profesión al menos de labios hacia fuera de admiración por la "experiencia chilena". Si se objetaba lo evidente, que por qué no se aplicaba la política de la Unidad Popular en los países europeos, la respuesta era de un tenor invariable: por las diferencias sociales, ese programa, el de la Unidad Popular era necesario en Chile, pero no en un país europeo, donde había más igualdad. Si siguiésemos la lógica de esta argumentación, debería haberse adoptado un camino de socialismo "no occidental"'-es decir, el modelo totalitario- en todas las que ahora son democracias industriales, en el siglo XIX, en Inglaterra, en Francia, en los Países Bajos... Aunque había cierta sociología que en los sesenta y setenta hablaba positivamente de "dictadura de desarrollo", para referirse a modelos "tercermundista", cuando no marxistas, no era esto lo que se quería decir cuando se hacía alusión a las bondades de la "vía chilena al socialismo".

Aquí ya existe una clara manifestación de un fenómeno que explica parte de las diferencias que ha suscitado el caso Pinochet: mientras en Europa se ha tendido a tener una mirada más o menos uniforme acerca de la evolución chilena, en estas tierras australes siempre hubo una fuerte división e incluso 
polarización, que de una manera muy atenuada pervive hasta nuestros días. Esto se abre en casos como el presente, aunque miradas serenamente las cosas, comparado con el siglo que hemos vivido, no existe una real fractura crítica en la sociedad política chilena.

Con todo, la pregunta sigue siendo, ¿por qué se escogió a Allende y por qué se efectuó esa lectura siendo Chile un país lejano y pequeño, cuyo sistema político apenas si había llamado la atención antes en Europa? Sería largo contestar estas preguntas y me limitaré a enunciar brevemente la siguiente hipótesis que subyace a mi presentación. Se trata de una fascinación europea con el "buen salvaje" que tiene hondas raíces históricas y, a la vez, no poco de frivolidad. Se ha analizado mucho a la Germania de Tácito en este sentido. Desde la época de la expansión europea no ha dejado de buscarse un El Dorado en América. Sabemos el papel político que jugó esta imagen en el XVIII europeo. La época del imperialismo y del nacionalismo oscureció algo esta imagen, pero resurge lenta pero seguramente en la primera mitad del siglo. Después se presenta con enorme impulso en los años de la Guerra Fría; la atmósfera cultural de los sesenta le da patente de seriedad intelectual sobre todo al abrigo de la rive gauche. Es una actitud que, por añadidura, no constituye un peligro inminente para los países europeos, ya que se dirige hacia zonas remotas. Cuando adquiere connotaciones amenazantes, vuelven a primar las consideraciones de seguridad.

La declinación del 68 y el desenlace en Praga, junto con una primera baja de voltaje de la Cuba de Castro -el "buen salvaje" por excelencia-, tenían el campo preparado para la "experiencia chilena". Sólo ahí se descubrió a la "democracia chilena", desde perspectivas que en algunos perduran hasta hoy día, negando que siquiera exista una democracia chilena en la actualidad. Indudablemente, esta reacción también se vincula con el empalidecimiento de los sistemas marxistas, o "socialismos reales", y la búsqueda de un sustituto, a pesar de que la Unidad Popular (leer al menos su Programa de Gobierno) los tenía como su horizonte paradigmático. Todo esto creaba una imagen inconmovible que, si cabía, fue más reforzada por el carácter que adquirió el gobierno militar que sucedió a la Unidad Popular. Esta realidad fue la que nunca fue comprendida en Chile por quienes estuvieron en la oposición contra la Unidad Popular o por quienes apoyaron al gobierno militar. Pero no son los únicos que han quedado perplejos por las características de las percepciones en el sistema internacional. 


\section{Los grandes y los pequeños: El otro aprendizaje (II)}

Pocas paradojas se han dado con carácter más mordaz que para aquellos que han debido defender al gobierno chileno ante el pedido de extradición de Pinochet, habiendo sido ellos opositores a Pinochet y, en algunos casos, haber sufrido vejaciones o vivido circunstancias crueles. Desde esta perspectiva, la reacción europea hasta el 16 de octubre pasado se reducía al tema de los derechos humanos. Esto es, se trataba de que la cultura política europea no podía aceptar como asunto de principios que se violaran los derechos humanos en lo que simple pero no del todo falsamente se consideraba la más antigua democracia del continente iberoamericano. No se detenían a pensar ni en el doble standard ni en el hecho de que casi todos ellos habían vivido una profunda transformación de sus ideas políticas, que fue uno de los presupuestos de la reconstrucción de la cultura política democrática en la segunda mitad de los ochenta.

La antigua adhesión de muchos de ellos a los sistema marxistas, se esfumó tanto con el contacto con el "socialismo real" como, aspecto de gran relevancia, con el contacto con la atmósfera política de Europa Occidental en el momento en que en ésta arreciaba la crítica no sólo anti-soviética, sino que antimarxista (o anti-leninista, sí se quiere). Se pulverizó la mirada esperanzadora que se había dado a los sistemas y movimientos totalitarios en los años que siguieron a la Segunda Guerra Mundial. Entonces, este fenómeno había tenido una influencia penetrante en la mirada revolucionaria que los mismos latinoamericanos mostraban como autoidentificación "original". Ahora, en cambio, se comenzó a hablar un lenguaje propio a la tradición democrática y a la aceptación -en diversos grados- de la importancia de una sociedad civil económica tanto para resguardo de la misma democracia, como para responder a los desafíos de la economía mundial y a los cambios en el conocimiento. En esta convergencia, el papel de la transición española tuvo un efecto claramente perceptible.

Este sector sería el que asumió las riendas de estos años de transición que, en líneas generales ya se ha efectuado, y recibió un aplauso universal. Nada le podía anunciar, hasta hace un año atrás, que se vería acorralado por los mismos a quienes se miraban como modelos y de quienes se recibían halagos. Para ellos, que paradojalmente muchos chilenos que comparten la politica de Madrid y Londres se lo enrostran burlonamente, se ha desencadenado 
una perplejidad ante el hecho de que ahora se le niega la legitimidad de su investidura y de su historia política reciente. Por si se quisiera mostrar otra paradoja, la negativa de diversos estados europeos de juzgar al líder kurdo Abdullah Ocalam es otra burla sanguinaria ante la cara del gobierno de Chile y de este sector. El desarrollo de estos hechos, es una constatación de que sencillamente en este mundo de convergencia-fenómeno real del que no cabe duda su existencia- también se da una cara paralela, aquella de la existencia de los fuertes y los débiles, que es la clara lección que Tucídides nos enseñara acerca de un rasgo esencial del sistema internacional, que por definición se constituye de relaciones asimétricas.

Por otra parte, estos hechos apuntan a problemas reales del sistema político chileno, aunque magnificados por el escrutinio desdeñoso de muchos chilenos y de observadores europeos. Sin embargo, a lo que aquí nos interesa señalar, es que esta otra mirada perpleja debe comprender el camino dificultoso del sistema internacional, que es una realidad de mil rostros.

A lo largo de más de tres décadas se ha proclamado insaciablemente en Chile, bajo diferentes lenguajes, que lo que el país requiere es adaptarse al "signo de los tiempos", como si fuera una cosa tan sencilla. Esto supone además que la mera apertura a esa renovación que viene desde afuera mejoraría sustancialmente la sociedad chilena. El sector al que me refiero ha sido especialmente sensible a esta interpretación. Ya sea porque se sostenía que se había hallado la piedra filosofal para unir, superándolos, a comunismo y capitalismo; porque Chile debía incorporarse a ese vasto movimiento que había cambiado la "correlación de fuerzas" en el mundo, avanzando hacia el socialismo representado por el paradigma de los estados marxistas. Lo mismo se quiso decir cuando se supuso que el país se incorporaba a un mítico frente "antimarxista", que no existía, al menos en la versión que se creía en Santiago. Debo añadir aquí a un paneconomicismo que cree que lo único que debe evaluar una sociedad es el "riesgo-país". Por último, por dar otro tipo de ejemplo, tenemos a las creencias en la originalidad de fuerzas a las que se supone oprimidas, y de las que se presume una originalidad y una identidad seudo-mítica. Esto no corresponde más que a las modas planetarias que ocurren en todas partes.

Estos chilenos han debido aprender que en el sistema internacional, aunque también es una sociedad internacional de fuerte convergencia, sólo puede ser una fuente de confianza si el país, o la sociedad, sabe adaptarse creativamente a su entorno, y desarrollar ese difícil arte de que los seres humanos 
sepan organizarse conjuntamente y sentir un hálito de optimismo en esta empresa, a pesar de todos los contratiempos. Asimismo, que la adaptación no consiste simplemente en cosechar aplausos, siempre caprichosos, sino que en saber sobrevivir sin necesariamente caer en la lógica de amigo/enemigo; aprendiendo que la cooperación es también una suerte de ser "uno mismo". El mundo podrá estar cruzado de tendencias planetarias; pero el hombre en términos colectivos se integra antes a una sociedad. Del carácter salvaje, bárbaro o civilizado (como Ortega adaptaba a Bachofen), de ese orden social dependerá en inmensa medida el carácter de su relación con el mundo y su integración a él.

Por último, este sector, en el que en un momento u otro han pertenecido todos los chilenos, ha debido aprender el valor del tan denostado "provincianismo". Toda sociedad es mirada, según la perspectiva, como "provinciana". ¿Qué podemos decir hoy día acerca de lo que tantas veces se ha ofrecido a sí misma como el paradigma del cosmopolitismo, la rive gauche? En otro tiempo, alabó las virtualidades liberadoras de la violencia. ¿Qué dice ahora? El provincianismo puede ser una fuente de fortaleza, en la medida que no se constituye como muro, sino como una forma de adoptar la universalidad, desafío a la que está sometida toda agrupación humana en los últimos siglos. También, nuestro país, representado por todos los gobiernos, ha tenido que experimentar la soledad, el aislamiento. No sólo durante el gobierno militar Chile estuvo aislado. En los últimos cuarenta años todos los gobernantes han tenido que experimentar una sensación de aislamiento. Era la queja de Alessandri ante EE.UU.; y de Eduardo Frei Montalva cuando se encontraba en los años sesenta; de Allende al volver de Moscú a fines de 1972, cuando no encontró la respuesta que daba por segura en el Kremlin. El caso del gobierno militar es demasiado evidente, lo tiene que aprender el Chile actual. Kosovo y Timor Oriental son escenarios de protección de los derechos humanos. No lo fue Chechenia ni lo es el Tibet. ¿Qué tiene que ver todo esto con la Madre Patria?

\section{El desarrollo del juego}

Ya antes de la guerra civil la situación española influía en la argumentación política chilena. El camino hacia la polarización en los momentos de la "crisis ideológica mundial" influyó en Chile, país extraordinariamente sensi- 
ble al acontecer mundial en el siglo XX. Hemos vivido y vivimos con especial simultaneidad las formas globales de identificación de las sociedades del siglo XX.

Como se decía, la guerra civil dividió a los chilenos. Tal como se moría en Madrid, muchos pensaban que había que morir en Santiago. Sólo que sucedería no en 1938, sino que en 1973. Más que en la derecha, la experiencia española caló profundiamente en la izquierda. Es una lástima que a largo plazo no fueran escuchadas las advertencias de Indalecio Prieto, Octavio Paz ha entregado un testimonio estremecedor acerca de su facultad visionaria. En Chile es bien conocida la posición de Vicente Huidobro, Pablo Neruda y Luis Enrique Délano, por nombrar a unos pocos que se identificaron con la República y el "antirracismo". No podemos olvidar las ricas polémicas que desde un punto de vista antagónico, desataron Hernán Díaz Arrieta, Alone, el sacerdote Osvaldo Lira y la interesante figura de Manuel Vega, hoy día olvidado (ila memoria!). No hay que pasar por alto a lo que en otra parte hemos llamado "observadores complejos": Gabriela Mistral y Joaquín Edwards Bello. Corresponden, en cierta manera, a los eximios españoles Miguel de Unamuno, José Ortega y Gasset y Salvador de Madariaga. Mientras los dos primeros se vieron forzados a la mudez, los chilenos entregaron su palabra que hoy día nos parece la sensatez misma.

En Chile, 1938 es un hito en la historia del país. De ahí, hasta 1970, la guerra civil y el franquismo fueron temas polémicos en la política chilena. El Frente Popular chileno se alimentó del desarrollo español, aunque las circunstancias eran bastante diferentes. Se desarrolló un catolicismo integrista que tiene fuertes huellas hasta nuestros días, con las transformaciones del caso; creció un catolicismo de signo progresista que por un momento, mucho más adelante, casi definió al catolicismo chileno. La derecha, el centro y la izquierda no olvidaron lo que creían las "lecciones de España"; es el eterno tema de los que se creen las "lecciones de la historia". Sabemos que no hay una lección unívoca. La historia es una apuesta de la que una cierta ceguera le es inherente.

Los exiliados, como tan maravillosamente nos ha recordado don José Ricardo Mortales, pasaron a integrar un patrimonio de la nación. También en Chile, los descendientes directos de españoles se dividieron. Incluso parte de los refugiados de 1939 se volvería a dividir en 1973. Esto no lo entiende nadie que se acerque a nuestra historia con los patrones de un catecismo político. Es parte de la divina impredecibilidad de la naturaleza humana. En los años se- 
senta el recuerdo de España estaba presente. El autor de estas líneas recuerda la vívida impresión que le causó el documental de gran calidad, "Morir en Madrid" a mediados de esa década, aunque no haya compartido la perspectiva del director. La idea de un cambio radical era mirada a través del desarrollo español, por anacrónico que hoy nos aparezca.

Las relaciones intergubernamentales no estuvieron libres de tormenta en la década de 1940, e incluso se llegó por momentos a la ruptura de relaciones. Influyó en este sentido el clima internacional de los años de la guerra y el predominio en Chile de coaliciones de centro-izquierda. Estas relaciones mejoraron en los cincuenta y sesenta, por los cambios políticos en Chile y por la modernización española. En general, sin embargo, el enjuiciamiento de España se relacionaba con la posición de cada uno en la política chilena. Por otra parte, Madrid, en lo referente a Hispanoamérica, abandonó su política cerradamente ideológica de la primera mitad de los cuarenta y asume más autoconscientemente un papel de Madre Patria, por medio de una versión más amplia de "hispanismo". Muchos recordamos como crecimos escuchando que los dictadores eran "malos", con la sola excepción de Franco. También, en la región de Valparaíso, numerosos vascos católicos, en general anticomunistas, abominaban a Franco, aunque en sus familias el tema no siempre generaba consenso.

Durante el gobierno de Eduardo Frei Montalva las relaciones económicas continuaron creciendo, y hubo buenas relaciones políticas. Pero la Democracia Cristiana venía de la Falange, que aunque apoyó inicialmente el alzamiento del 18 de julio, luego, influida por visión de Maritain y Bernanos, tomaría una equidistancia ante el conflicto. Esto todavía dejaba huellas en los sesenta, y Madrid se quejaría porque Frei en su gira a Europa (la primera de un Presidente chileno) dejaría fuera de itinerario a España.

\section{Nace el "juego de espejos"}

Con el gobierno de la Unidad Popular estaban dados todos los presupuestos para una relación confrontacional. Parecerá extraño, pero las relaciones fueron sustancialmente buenas. La Moneda necesitaba superar un presunto aislamiento que se temía, y España fue una fuente de créditos cuando la producción de billetes no pudo mantener a la economía. Desde el punto de vista 
de un gobierno en la situación del chileno, esto no tiene nada de extraño. La pregunta hay que hacérsela al lado español.

Aquí jugaron diversos factores. Como se decía, el franquismo renunció a exportar su ideología después de 1945. Por lo demás, no podía darse el lujo. Se contentó con la no desdeñable política del "hispanismo" y el flujo de becados latinoamericanos en las universidades españolas. Su modernización económica, que fue una suerte de "milagro español" en los sesenta, no dejó de llamar la atención en América del Sur. Existía el antecedente de Cuba, donde Franco se negó a seguir las aguas norteamericanas, claro está que era un caso muy simbólico en la historia española. Pero, con todo, se podía repetir ante Allende y así mostrar algo que se pareciera a una cara "progresista" en política exterior, cuando en lo interno el contraste con Europa Occidental no podía ser mayor.

También jugó un papel en su política interna, ya que la "experiencia chilena" no dejó de provocar en España el mismo embeleso que en el resto de Europa Occidental. Por añadidura, la prensa y el mundo de opiniones podía hacer oposición al franquismo tardío por medio de apoyar a Allende; esto era permitido por el gobierno español como vía de compensación. La intelligentzia de izquierda española se identificó calurosamente con la Unidad Popular, y uno de sus exponentes más radicales, que tenía su paradigma en el marxismo en el poder, Joan Garcés, ejerció una fuerte y todavía no claramente estudiada influencia sobre Allende mismo. Aquí, como en París, en Londres y en Roma se miraba una utopía, a la que tenía que seguir la antiutopía. Por sobre todo, es aquí de donde arranca la primera influencia visible de la historia política chilena en la Madre Patria, aunque por cierto, no podía tener el peso que los sucesos españoles ejercieron sobre Chile. Aquí tenemos el "juego de espejos", sin el cual no se podría aquilatar el alcance del caso Pinochet.

Entretanto, la polarización creciente en Chile era verbalizada con imágenes extraídas de la guerra civil española. El lema "No a la guerra civil», que era casi lo mismo que decir "todo el poder para nosotros" aludía con claridad a 1936; que si había confrontación habría "un millón de muertos". La cifra emblemática era un lugar común en esos años. La estrategia de paramilitarización obedecía al espectro de la guerra civil, y de la parálisis política de las Fuerzas Armadas en Chile en momentos en los cuales la Constitución iba deviniendo en letra muerta. Los intentos finales de negociación tenían como expectativa de fracaso un desarrollo parecido a julio de 1936. La estrategia 
que ambos bandos usaron para el 11 de septiembre era repetir y/o no repetir ese año. Especialmente la preparación de la toma de poder por parte de las fuerzas armadas chilenas se hacía para evitar el copamiento de sus unidades, y golpear con fuerza para inmovilizar instantáneamente a los adversarios. Los que avanzaban sin transar querían mantener a parte de las fuerzas armadas en sus cuarteles y a la otra parte teniendo que evaluar si atacaba a sus compañeros de arma. Un poco espectralmente, los contendientes volvieron a combatir la guerra civil, lo que en cierta manera demuestra otro rasgo, negativo en este caso, del provincianismo chileno.

\section{Fallido franquismo «a la chilienne» $\mathrm{y}$ consolidación de gobierno militar}

El juego de espejos continuaría, y lo vemos, hasta nuestros días. Entre 1974, la Declaración de Principios, y 1977, el Discurso de Chacarillas, Pinochet tienta con la carta de un franquismo para Chile. Esto es difícil de probar taxativamente, pero es nuestra convicción. El viaje de Pinochet a los funerales de Franco simbolizó esa adhesión expresa. Sólo que faltaban muchos factores. Chile tenía mucho más desarrollada una tradición constitucional que España en 1936. El 11 de septiembre había surgido de una crisis radical de la sociedad política chilena, pero no de una guerra civil. El entorno internacional, por las razones antes explicadas, se abatía no sin cierta justicia/injusticia sobre el país austral. Por añadidura, la presión de Washington, que ya se había distanciado de Chile a partir de 1974, se hizo muy fuerte con la llegada de Jimmy Carter al poder. Todo hizo que el régimen pasara a la estrategia de "democracia autoritaria" o después, "democracia protegida", en virtud de la cual, en la segunda mitad de los ochenta, por medio de una transacción, se efectuó la transición a la democracia, aunque con algunos elementos, creo que secundarios, extraños a la tradición democrática. Se esfumaba el modelo franquista hacia 1980, pero se iniciaba la presencia de otro modelo español. En todo caso, en su estilo, el gobierno militar chileno se había consolidado, aunque a la vez y para no perder su labor, hubo de preparar su propio retiro.

En España el 11 de septiembre causó una viva emoción. La generación joven o que estaba en su temprana madurez participó plenamente de la emoción de sus congéneres de Europa Occidental. Las relaciones de gobierno a 
gobierno, aunque cueste creerlo, en vida de Franco, no fueron tan buenas como durante la Unidad Popular. Hubo dificultades económicas, por las generosas concesiones entregadas a empresas españolas, con disposiciones que chocaban con la "reforma económica", una de las vigas maestras del gobierno militar chileno. Por otro lado, parte del aparato franquista quería disociarse suavemente del sistema, y no le agradaba ser mirado como modelo por un gobierno militar sudamericano, sobre todo tratándose del espectacular caso chileno.

\section{El rasgo crítico de Chile en la transición española}

Muerto Franco, los nuevos dirigentes que pusieron en marcha la transición hicieron gala de fe democrática, atacando al gobierno chileno, aunque halagaban incesantemente a Castro. Suárez destacó especialmente en esta línea. Era una prueba de "corrección política" no sólo ante la izquierda que había estado hasta ese momento en la clandestinidad, sino que sabiamente se la quería incorporar al juego democrático. En esto, incluso el Partido Comunista de Santiago Carrillo se adelantó a los socialistas. (Entre paréntesis, ¿por qué Garzón, en aras de una justicia absoluta, no abre juicio a Carrillo por la matanza de Paracuellos?)

Más importante, la puesta en marcha de la transición española, que se ve consolidada con el triunfo del socialismo en 1982 -pero aceptando el "modelo occidental"-, tuvo una influencia visible en la transformación de la cultura política chilena en el exilio. Por una parte al haber dado un campo de acción a la Democracia Cristiana; por otro lado, al haber ayudado a entregar una nueva visión política a la antigua izquierda en Chile. También al haber entregado los recursos correspondientes. Todo esto daría su fruto en la "transición corta" en Chile, entre 1988 y 1990. La España de los noventa, incorporada a la modernidad dentro de lo que cabe, es también espejo del Chile de los noventa, con sus problemas de modernidad inacabada pero no irreal.

\section{Los noventa: olvido y memoria}

Junto con el alza y los límites de la fama del "modelo chileno" (reforma económica completada por la transición a la democracia), nunca se dejó de 
lado a Pinochet como uno de los símbolos del mal del siglo XX. En la vida descolorida de la modernidad, unos pocos símbolos todavía pueden arrastrar a un ardor $\rightarrow$ lo que parece tal- y proyectar una fuerza política. Si además existe consenso en la condena moral, nos encontramos con un muro que ni el estado ni la política chilena pueden penetrar. Más todavía, muchos chilenos comparten la posición de España y el principio de extraterritorialidad aplicado a este caso. Es indudable que en Chile la detención de Pinochet ha desatado una crisis grave aunque no mortal. Por otro lado, aunque los gobiernos inglés y español han ejercido un abierto doble standard, es evidente que no sufrirán un castigo político interno por esta actitud; todo lo contrario, pueden ser premiados y, aparte de las simpatías de cada uno de sus líderes, no tienen nada que perder al mantener la política que han seguido.

Sin embargo, ¿no escamotean estas consideraciones el asunto principal, de sí Pinochet debe ser juzgado o no? Si la respuesta es positiva, no habría líder de un sistema autoritario que acceda a transitar a una democracia y, desde luego, habría que renunciar a la posibilidad del establecimiento de un "estado de derecho" en porciones no insignificantes del mundo actual. También hay que considerar el tema de la construcción de la paz, que desde el Congreso de Westfalia en adelante, salvo victoria absoluta como en 1945, ha significado una transacción. Un famoso cuadro de Rembrandt ("Minerva protege a la Paz [de las amenazas] de Marte", 1629-1630) simboliza este problema. Esto nos lleva a pensar otra dimensión del caso Pinochet en la evolución del sistema internacional en el mundo post-Guerra Fría.

\section{El orden internacional y la dinámica de la democracia}

En la situación de convergencia en que se encuentran los grandes actores del sistema internacional en la post-Guerra Fría, es decir, las grandes potencias, han respondido a las tendencias de nuestra cultura política finisecular que ha hecho de la intervención humanitaria un punto central del programa de acción. Por humanitaria que sea, ello no puede efectuarse sin el recurso de la "amenaza de uso de la fuerza". Y esto no puede proferirse si no se está dispuesto a emplearlo. Existen situaciones en las cuales se puede decir con cierto grado de certeza que el no empleo de este recurso ha permitido grandes tragedias, como en Ruanda en 1994. En la actualidad hay grandes apuestas 
en su uso en Kosovo y en Timor Oriental. La experiencia de Bosnia, en 1995, parece haber tenido un resultado positivo. Otras, como ya se anotaba, en Chechenia y en el Tibet, parecen prohibidas por razones de perogrullo. Remotamente, pero no del todo imposible, ni un país como Chile, dado que es el "caso de turno" puede verse sometido a una intervención de este tipo.

¿Existe algún criterio que nos permita decidirnos en qué caso es necesaria y en cual caso sería contraproducente este tipo de acción? Aparte del simple tamaño y poder de disuasión (Rusia y China), me parece que existe un criterio. Lo más probable es que el mundo siga dividido entre una barbarie y una zona de civilización (me gusta más esta expresión antes que la de "desarrollado" o "subdesarrollado"), y que las zonas de agonía no se evaporarán con rapidez, si es que alguna vez sucede. En ese sentido, este será un problema recurrente, en la medida que sigamos con la idea de que se requiere un horizonte de "civilización política" mínimo para ser un miembro de una sociedad internacional. Cuando los actores de la política interna de un Estado o de una región determinada alcancen un acuerdo que mejora su realidad política (la paz, el desarrollo, la democracia), en suma, se alcance o se marche en dirección del "estado de derecho", una elemental disposición de prudencia indicaría que la comunidad internacional debe acatar su resultado.

Más aún, si es que esa comunidad internacional no podrá hacer todo en todas partes. Mayormente, todavía, si es que sus propios actores tienen que hacer la paz al interior de sus sociedades usando acuerdos quizás moralmente imperfectos desde un punto de vista absoluto y ahistórico, pero claramente superiores a aquel de la victoria total que se asemeja a la "tierra quemada". Nuevamente, como aprendizaje de la raíz histórica del caso Pinochet, debemos meditar acerca de la gran condición de supervivencia en el sistema internacional, que el orden interno de una sociedad establezca una vida civilizada que, con palabras de Ortega, esté "a la altura de los tiempos". 